\title{
Guided tissue regeneration in the distal area of mandibula - case report
}

\author{
Irena Georgieva
}

\author{
Department of Periodontology and Dental \\ implantology, Dental faculty, Medical University \\ Varna, Bulgaria;
}

\section{Abstract}

Background: Applying the periodontal regenerative surgical techniques improve the long-term clinical outcomes of teeth which are periodontally compromised by intrabony or inter-radicular defects. Periodontal diseases affecting the distal surfaces of multirooted teeth can be very serious problem. Different surgical techniques are proposed for treatment of infrabony defects in the distal zone of dentition. A guided tissue regeneration is a proper technique that can be used for treatment of deep intrabony defects. The success of combined technique (barrier membrane plus bone replacement graft) would lead to complete elimination of the vertical component of bone defect by bone fill and clinical attachment level gain.

Purpose: The aim of this case report is to present and analyze the healing result after regenerative periodontal therapy distally to second mandibular molar using resorbable collagen membrane and bone grafting with bovine porous bone material.

Material and methods: A vertical intrabony defect, affecting the distal surface of the second mandibular molar, is established. A combined regenerative therapy (bone graft with a barrier membrane) is used for reducing the pocket depth and achieving clinical attachment level and bone gain.

Results: The guided tissue regeneration with collagen membrane and xenograft resulted in increase of clinical attachment level of a severely compromised tooth limiting recession of the gingival margin and decrease in the periodontal pocket depth. 
Conclusion: The combined regenerative therapy with barrier membrane and bone replacement graft presents satisfactory outcome results in case of severe attachment loss and loss of alveolar bone to the apical third of the root.

\section{Keywords: guided tissue regeneration, bone grafting, infraosal bone defects, mandibular molars}

\section{Background}

Applying the periodontal regenerative techniques improve the long-term clinical outcomes of teeth which are periodontally compromised by infrabony or inter-radicular defects. According to the classification by Goldman and Cohen (1958), infrabony defects are those where the base of the pocket is located in apical direction with respect to the residual alveolar bone crest and they affect primarily the root surface of one tooth, while the interdental craters are vertical defects that affect two adjacent root surfaces to a similar extent.(1)

Periodontal inflammatory disease affecting the distal surfaces of multirooted teeth can be very serious problem. It is a challenge for the clinician to access the distal surfaces of mandibular molars for proper instrumention. The nonsurgical periodontal therapy is usually impossible to control the periodontal infection in deepest part of deep periodontal pockets $>7 \mathrm{~mm}$. The resective periodontal surgery techniques result in complications, associated with removal of supportive alveolar bone that affect the long-term prognosis of the treated teeth.(2) The postoperative exposure of distal root surfaces can lead to dentin hypersensitivity, root caries or can embarrass the proper personal oral hygiene in this zone.(3) For this reason different surgical techniques of periodontal regeneration were introduced to eliminate these complications.

Guided tissue regeneration (GTR) is a proper surgical technique based on the placement of barrier membranes that impede the proliferating of fast growing epithelial and connective tissue cells of the flap into the wound and to guide the migration of low growing periodontal ligament cells on the exposed root surface and regeneration of alveolar bone cells.(4) This technique is based on the hypothesis that periodontal ligament and perivascular cells have the potential for regeneration of the attachment apparatus of the tooth. In periodontal regeneration with GTR, the healing response is a result of the reconstitution of a new periodontium, that involves the regeneration of alveolar bone, periodontal ligament, and new cementum.(5) The combined technique of GTR plus bone grafting is introduced for better clinical and histological results. $(6,7)$ The success of combined technique would be the complete elimination of the vertical component of bone defect by bone fill and clinical attachment level gain. The results of different studies indicate that clinical attachment gain obtained following GTR treatment can be maintained on a longterm basis. $(8,9)$ The results obtained with the combined procedure were more stable over time.(10)

Bonegraft materials have been discussed for years in literature.(11,12) Bovine porous bone material (BPBM) is a proper choice because of its high biocompatibility, highly osteoconductive scaffold - surface porosity that allows fast penetration and adsorption of blood and serum proteins, which can promote cell adhesion and differentiation, easy handling and elicits no systemic immune response. This material is proper to maintain the space that is very essential for bone regeneration and support the overlying resorbable membrane.(11-13) 
Collagen membranes (CM) are preferred because of their biocompatibility, easily handling, long lasting resorption time of 2 to 4 months, no need of second surgery. $(14,15)$

The thickness of the gingival tissues covering the barrier material must be considered if post-surgical recession is to be minimized or avoided. Sites with a gingival thickness of $>1 \mathrm{~mm}$ exhibited less gingival recession post-surgery than sites with a gingival thickness of $<1 \mathrm{~mm}$.(16)

The combined therapy (GTR with resorbable collagen barrier membrane and bone graft) is the gold standart for regeneration in treatment of deep intrabony defects. The literature survey reports that this technique shows good results in treatment of 3-walls and 2-walls vertical bone defects.

The aim of this case report is to demostrate the efficiency of guided tissue regeneration (GTR) with barrier collagen membrane (CM) and derived bovine bone material (DBBM) in treatment of infraosal bone defect in case of very deep periodontal pocket $(13 \mathrm{~mm})$, clinical attachment level loss to the apex of the tooth and tooth mobility (grade 1 ) with conventional full thickness flap approach and subsequent coronally replacement of the flap in the distal zone of the mandibula.

\section{Case Description}

\section{Material:}

A patient is a 34 years old male, non-smoker, with no systemic diseases, no allergies and no medicaments intake. He came with complaints of pain and discomfort in right lower distal region of dentition, because of deep periodontal pocket located distally to mandibular second molar. A medical history and periodontal status (probing depth, clinical attachment level, height of keratinized gingiva, presence of gingival recession, mobility) were recorded.

The periodontal probing depth (PPD) at the distal aspect of tooth \#47 is $13 \mathrm{~mm}$ and the probing attachment level (PAL) loss is approximately $14 \mathrm{~mm}$ (fig.1 and fig.2). PPD is determined as the distance between the gingival margin and the bottom of the pocket, and the PAL is determined as the distance between the CEJ and the probing bottom of the pocket.

Mobility grade I of tooth \#47 is reported. The width of keratized gingival tissues on the vestibular side of the tooth is approximately $4 \mathrm{~mm}$ and on the lingual side $-6 \mathrm{~mm}$. All the measurements were recorded by means of University of North Carolina 15 (UNC 15) periodontal probe. 


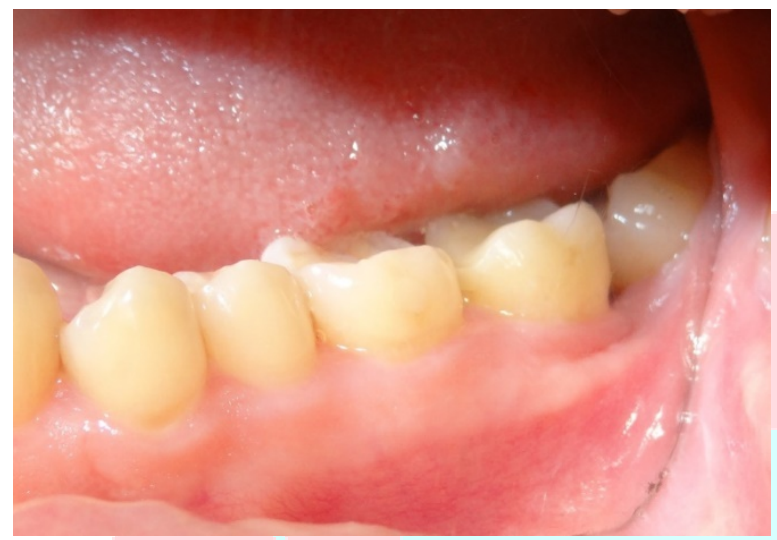

Pic.1 Vestibular preoperative view

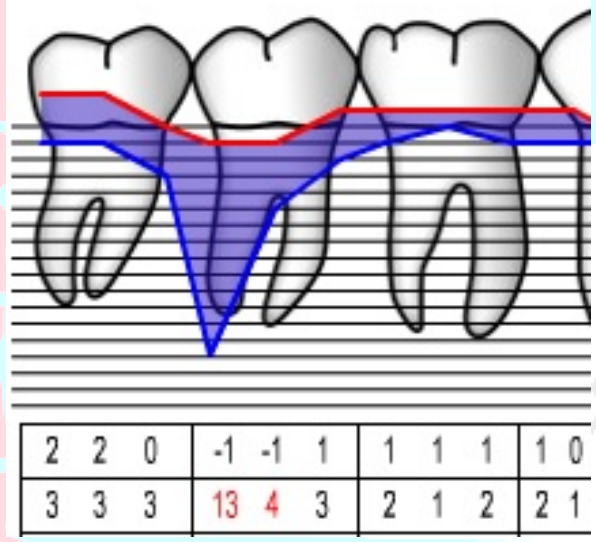

Fig.1 Vestibular view

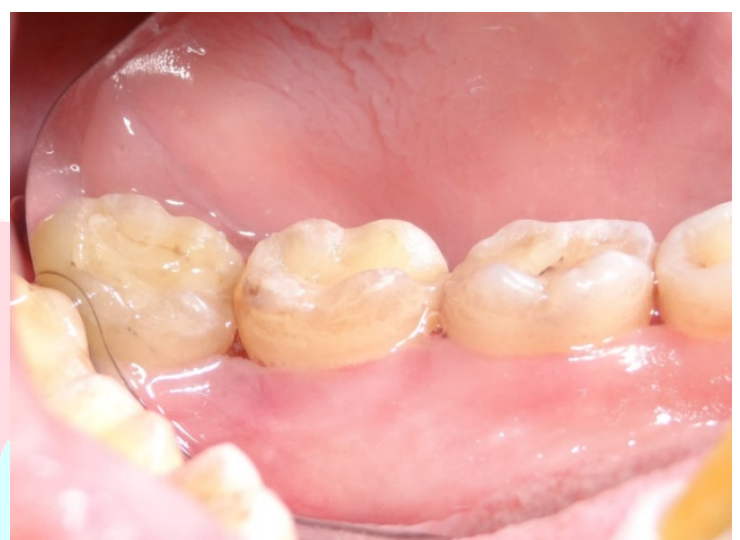

Pic.2 Lingual preoperative view

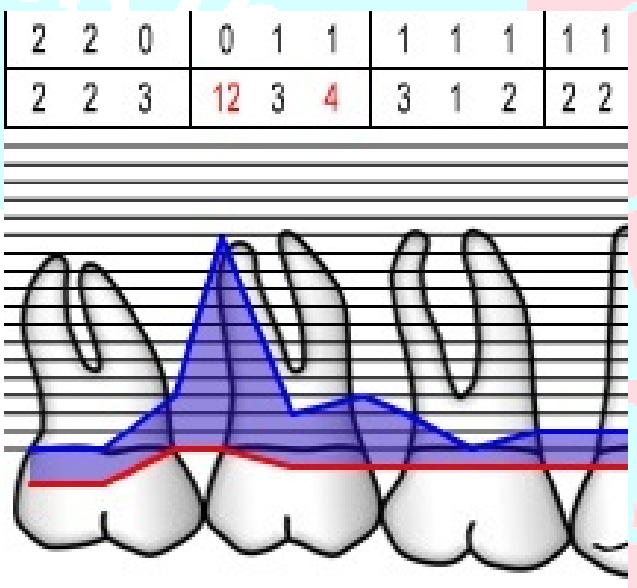

Fig.2 Lingual view

After EOD assessment is reported that the right second molar is non-vital. An endodontic treatment is done and a periapical radiograph of the tooth is taken using a parallel technique immediately after the endodontic treatment. The radiograph showed the presence of deep intrabony defect. (pic.3) 


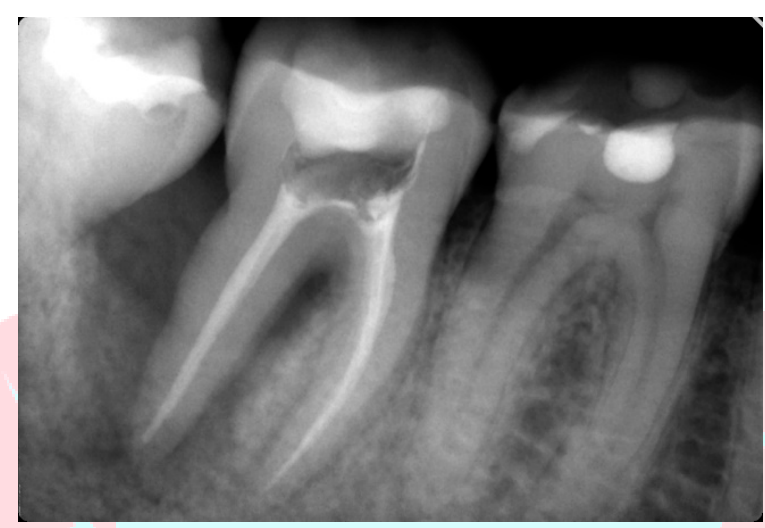

Pic.3 Radiographic preoperative view

The patient is informed about the diagnosis and prognosis of his periodontal disease and about the treatment plan and an informed consent is signed by him before surgical treatment.

Before the surgical therapy the patient is instructed for proper oral hygiene to obtain adequate score of plaque index of O'Leary $(\leq 10 \%)$. A modified Bass brushing method for cleaning the teeth surfaces is performed to the patient.

Scaling, polishing and root planing of the hard tooth surfaces are performed.

The surgical treatment is scheduled 6 weeks after the nonsurgical mechanical therapy is completed.

\section{Method:}

The deep intrabony defect is treated with combined regenerative therapy - GTR with bioresorbable collagen membrane and bone replacement xenograft and coronally advanced flap for covering the membrane.

\section{Treatment:}

After adequate local anesthesia with Ubistisin 4\% (1:100 000 epinephrine), the surgery technique is initiated with the placement of horizontal intracrevicular incision buccaly and lingually from the distal surface of tooth \#48 to the distal surface of tooth \#46 using a surgical blade 12D. The horizontal incisions are followed by one vestibular apically divergent vertical releasing incision mesial to the interdental papilla of first mandibular molar (46), connected with the intracrevicular incision and extending 3-4 $\mathrm{mm}$ apically into the lining alveolar mucosa, using surgical blade 15 . The releasing incisions facilitate displacement of coronally advanced flap. No vertical releasing incisions are performed on the lingual side.

A triangular full mucoperiostal buccal flap and envelope lingual mucoperiostal flap are elevated with a periostal elevator.

An infrabony defect is presented on the distal surface of the second mandibular molar.(pic.4) It has a complex morphology consisting of a three-wall component in the apical portion of the defect, and two-wall 
components in the superficial portions. The bone defect is curetted, a debridement of the diseased exposed root surface of tooth 47 is done by means of specific-area Gracey curettes and universal Younger-Good curette until a smooth, clean and hard root surface is obtained. The root surface in the anatomical bone dehiscence must be avoided due to damaging of the connective tissue fibers inserting into the cementum near the bone crest. An irrigation of the bone defect with saline solution is done.

A horizontal incision is made through the periosteum to facilitate the displacement of the flap and reduce the muscle tension in time of suturing.

The intrabony defect is filled with bone replacement material. A resorbable collagen barrier membrane was placed over the defect on the top of the bone replacement graft. By coronal displacement of the flap, the membrane is completely covered by the soft tissues.

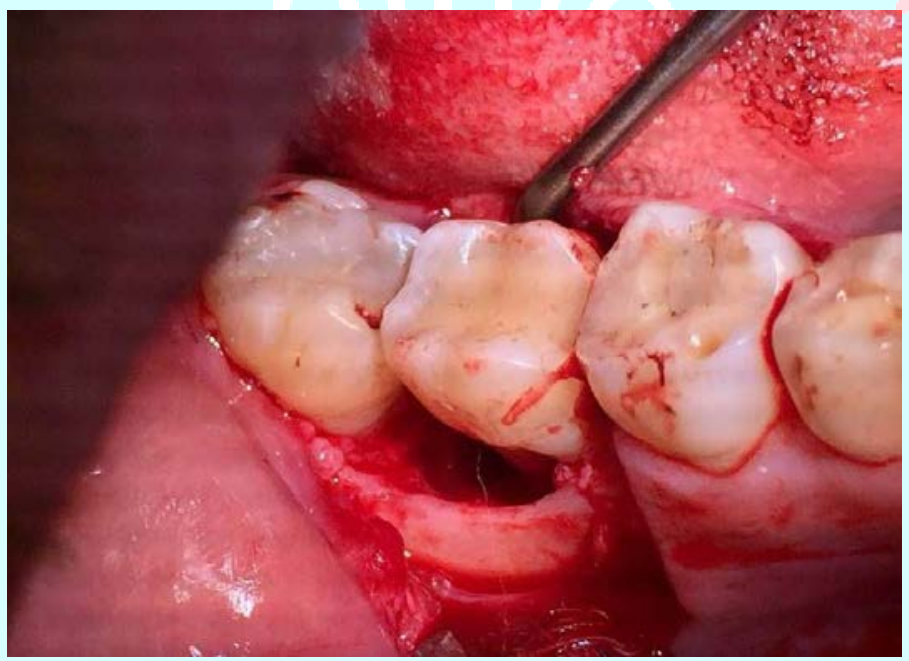

Pic.4 Incisions and elevation of the mucoperiostal flap

Suturing of the covering flap starts using one interrupted mattress internal horizontal suture over the collagen membrane in the interdental zone between teeth 47 and 48 . The purpose of this first mattress suture is to reduce the tension in the flaps in the defect-associated area. Continuing with suturing of the releasing incision from apically to coronally and horizontal incisions with direct loop sutures without any residual tension. The suture material that is used for suturing the mucoperiostal flaps is non-absorbable monofilament $5 / 0$ sutures (Dafilon ${ }^{\circledR}$ ) to obtain primary tension-free closure of the surgical wound. Primary closure of the flap was obtained. The sutures are maintained during the healing period.

The aim is to obtain shallow pocket by reconstruction of the destroyed periodontal attachment apparatus.

Postoperative instructions were given to the patient. In order to prevent wound infection, a systemic antibiotic therapy is prescribed to the patient before and during the first weeks after membrane application - Augmentin $1000 \mathrm{mg}$ (amoxicillin plus clavulanic acid), 2 times per day for 10 days. The patient also received analgesic and anti-inflammatory therapy. 0,12\% chlorhexidine mouth rinse solution (Eludril Perio ${ }^{\circledR}$ $0,12 \% \mathrm{CHX}$ ) was prescribed three times daily for 2 weeks and the patient was informed to avoid brushing 
and flossing the teeth in surgical area in the postoperative period until the surgical sutures have to be removed.

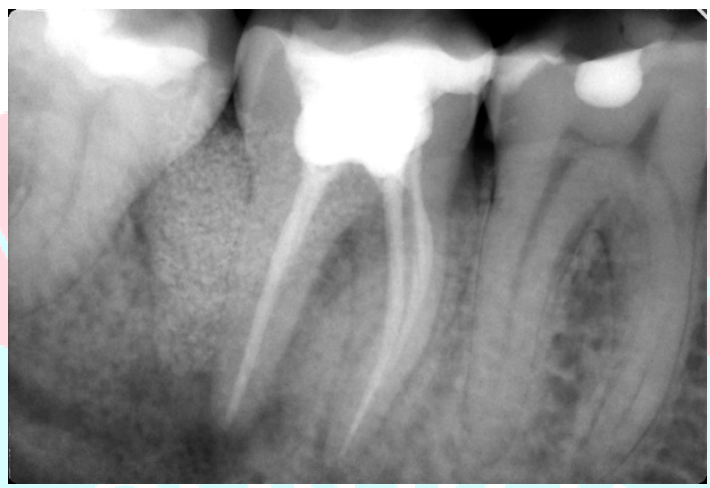

Pic.5 Control radiographic image postoperatively (immediately after surgical manipulation)
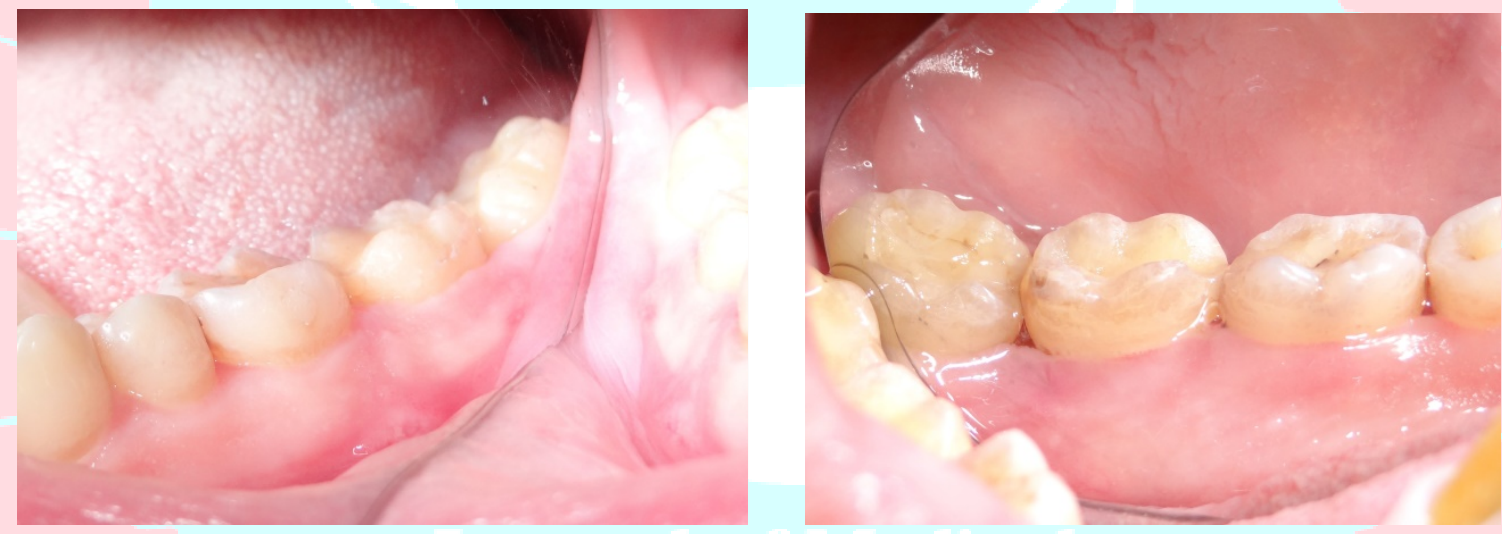

Pic.6 and Pic.7 1 month after surgical manipulation

No postoperative complications are recorded during the post-operative healing period - membrane exposure, flap dehiscence, suppuration. The patient was recalled 7 days after the manipulation for control visit and 14 days after for sutures removal. Excellent early healing in the absence of pain or discomfort is evident at the 2-week suture removal.

An adequate healing of the surgical wound is noted. The mouth rinse solution is changed with $0,05 \% \mathrm{CHX}$ solution (Eludril Care ${ }^{\circledR} 0,05 \%$ ) for still 4 weeks. After 2 weeks the patient was instructed for mechanical cleaning to brush his teeth in the treated zone using a soft postoperative toothbrush (Elgydium clinic ${ }^{\circledR}$ 15/100) and Stilman brushing method. In the first 2 months after surgical manipulation the patient is recalled every week for control visits and prophylaxis. 


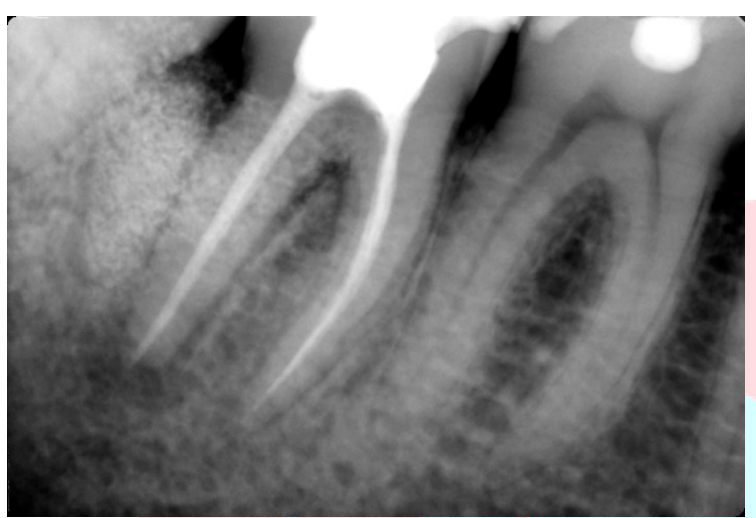

Pic. 86 months after surgery

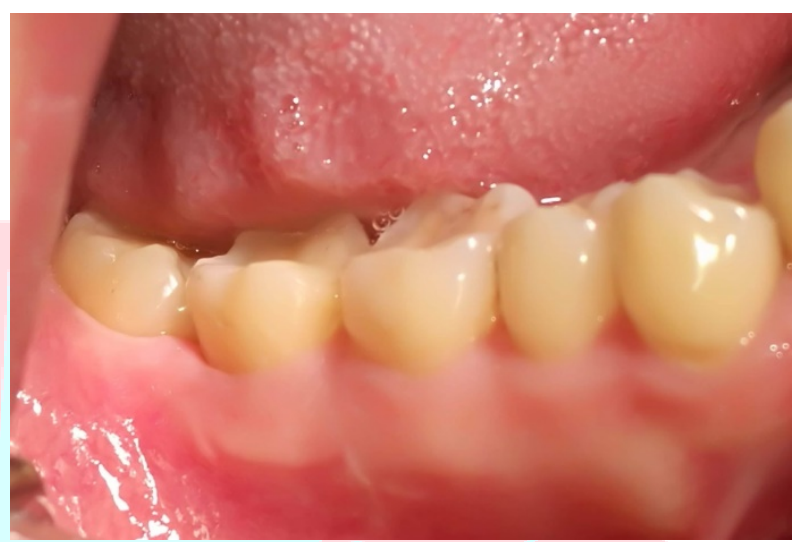

Pic.9 8 months after surgery

After that the patient was recalled every month in postoperative following period for control visits and prophylaxis.

\section{Results}

The patient was followed-up and the results are stable 12 months later.A radiograph is taken 6 months after the surgical therapy. The radiograph showed elimination of the defect and persistence of mineralized granules of bone replacement graft embedded in the newly formed mineralized tissue.(pic.8) Another radiograph is taken again 1 year after surgery manipulation.(pic.10)

The clinical outcomes also show healing with shallow probing depths $(4 \mathrm{~mm})$ and elimination of the defect. The PAL and PPD were measured and compared to the baseline before treatment. A gain of clinical attachment level (CAL) is achieved on the distal surface - approximately $10 \mathrm{~mm}$ PAL gain. (fig.3 and fig.4)

The patient was satisfied with the received result of the surgery.

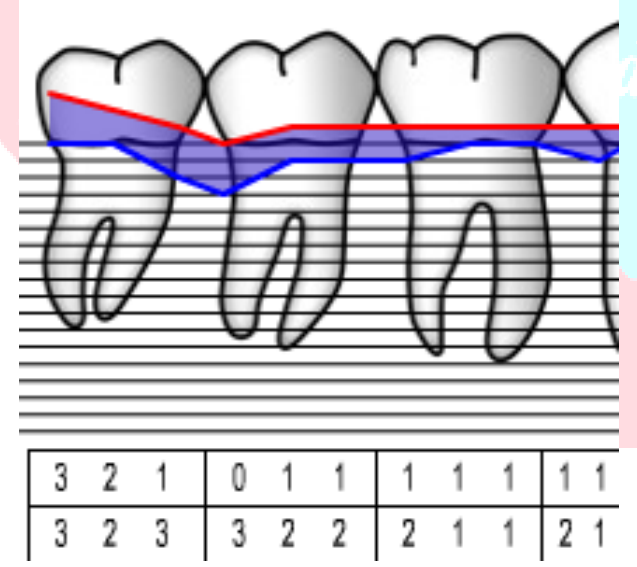

Fig.3 Vestibular view postoperatively

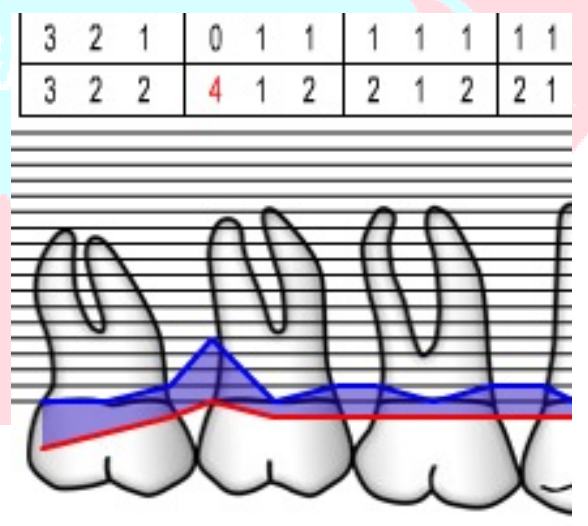

Fig.4 Lingual view postoperatively 


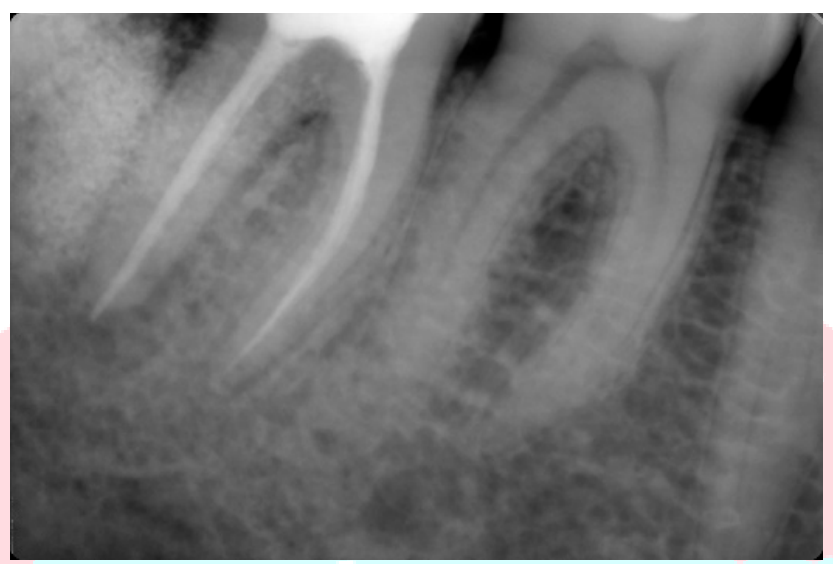

Pic.10 1 year after surgery

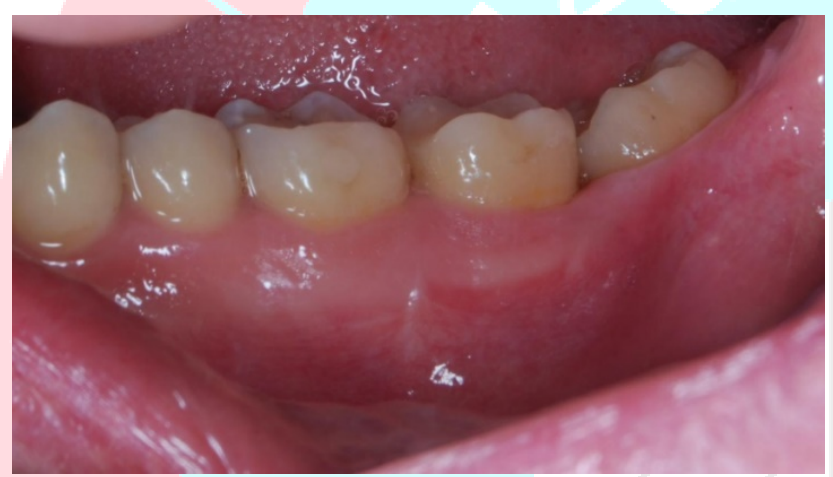

Pic.11 Vestibular view 1 year after

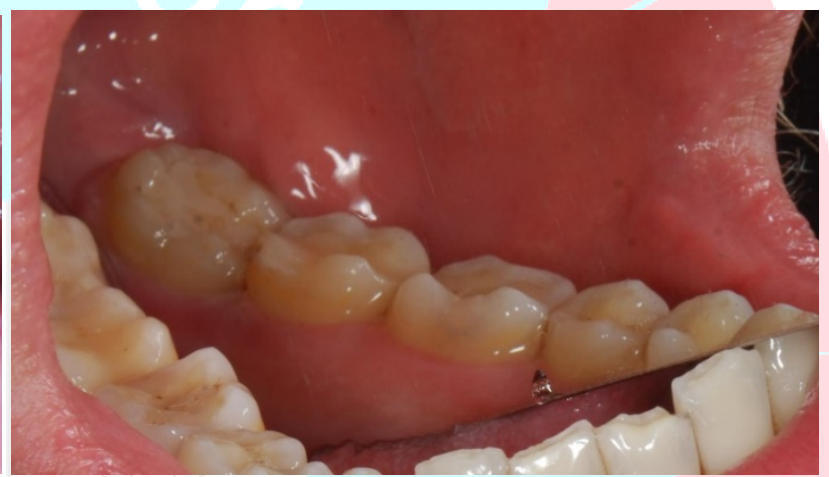

Pic.12 Lingual view 1 year after

\section{Discussion}

The intrabony defects in the distal region of the mandibula can be successfully treated with different surgical approaches resulting in periodontal regeneration. Clinical case reports show results that GTR technique lead to gain in clinical attachment level. $(17,18)$

Different studies by different authors showed the usefulness of barrier membranes(5), demineralized freeze dried bone allograft (DFDBA)(19), combination of barrier membranes and grafts(20) and the use of enamel matrix derivatives(21) in periodontal regeneration. The data and evidence from these studies don't proposed a certain approach among different regenerative possibilities.

Guided tissue regeneration technique is reliable method for surgical therapy of infraosal bone defects and is associated with a low risk of complications - post-operative pain, suppuration, perforation of the flap or membrane exposure. After surgery if there is a membrane exposure, the exposed coronal part of the membrane be infected by the microorganisms in the oral cavity and this will result to gingival recession. 
In one study Sanz et al. (2004) revealed that all sites that are surgically treated with membranes presented less complication during combined therapy resulted in greater PPD reduction, PAL gain and defect fill than only the use of bone replacement graft (13) and than access flap surgery alone (22).

In the literature there are many published surveys about the success in treatment of infraosal bone defects with combined regenerative surgery. Camelo et al. (1998) and Mellonig (2000) revealed histologic data reporting that the use of bone replacement graft under a membrane may result in partial regeneration of the periodontal tissues, but in this approach most of the defects were filled with deproteinized bone particles. $(13,20)$ These results respond to the results reported by Paolantonio et al., who observed a limited bone formation in the vicinity of the preoperative existing bone, treated with xenograft and a collagen membrane. According to their findings the bigger part of the space in the defect was filled by xenograft particles embedded in neighbouring tissues.(23)

The results of that case report support the success of combined regenerative approach in periodontal regeneration of intraosal bone defects in the distal zone of the mandibula, indicated that there was a significant clinical attachment level gain, reduction of the pocket depth, no postoperatively gingival recession and no loss in the width of the keratized gingiva 12 months postoperatively.

Key steps in such cases are the precise assessment of the patient and of the defect, the ability to choose the most proper surgical regenerative approach and appropriate regenerative materials, and the possibility to protect the surgical wound in the postoperative healing period from contamination.

\section{Conclusion}

This case report demonstrated that the proposed combined GTR technique with bioabsorbable pericard membrane and bone grafting with xenograft material in periodontal therapy of deep infraosal defect at the distal aspect of mandibular second molar resulted in significant reduction in the periodontal pocket depth (PPD), probing attachment level (PAL) gain and bone fill.

\section{Abbreviations:}

CAF - coronally advanced flap

GTR - guided tissue regeneration

BPBM - bovine porous bone mineral

DBBM - derived bovine bone material

CM - collagen membrane

PAL - probing attachment level

PPD - periodontal pocket depth

CEJ - cemento enamel junction 


\section{References}

1. Goldman H, Cohen D. The infrabony pocket: classification and treatment. J Periodontol 1958; 29(4): 272-291.

2. Buchanan SA, Robertson PB. Calculus removal by scaling/root planing with and without surgical access. J Periodontol 1987; 58:159-63.

3. Sarpangala M, Suryanarayan MA, Shashikanth H, Shanker KR, Mohamed M, et all. Etiology and occurrence of gingival recession - an epidemiological study. J Indian Soc Periodontol. 2015 Nov-Dec; 19(6): 671-5

4. Caton JG, DeFuria EL, Polson AM, et al: Periodontal regeneration via selective cell repopulation, J Periodontol 58:546, 1987.

5. Gottlow J, Nyman S, Lindhe J, Karring T, Wennstro"m J. New attachment formation in the human periodontium by guided tissue regeneration. Case reports. J Clin Periodontol 1986 Jul;13(6):604-16

6. Schallhorn RG, McClain PK. Combined osseous composite grafting, root conditioning, and guided tissue regeneration. Int J Periodontics Restorative Dent 1988;8(4):8-31.

7. Needleman IG, Giedrys-Leeper E, Tucker RJ, Worthington HV. Guided tissue regeneration for periodontal infra-bony defects. Cochrane Database Syst Rev. 2001;(2):CD001724

8. Becker W, Becker B. Clinical applications of guided tissue regeneration: surgical considerations. Periodontology 2000 1993; 1(1):46-53

9. McClain PK, Schallhorn RG. Long-term assessment of combined osseous composite grafting, root conditioning, and guided tissue regeneration. Int $\mathrm{J}$ Periodontics Restorative Dent. 1993;13(1): 9-27.

10. Machtei E, Grossi S, Dunford R, Zambon J, Genco R. Long-term stability of class II furcation defects treated with barrier membranes. J Periodont. 1996, 67(5):523-527

11. Fugazzotto PA. GBR using bovine bone matrix and resorbable and nonresorbable membranes. Part 1: Histologic results. Int J Periodontics Restorative Dent 2003;23:361-369.

12. Fugazzotto PA. GBR using bovine bone matrix and resorbable and nonresorbable membranes. Part 2: Clinical results. Int J Periodontics Restorative Dent 2003;23:599-605

13. Camelo M, Nevins ML, Schenk RK, et al. Clinical, radiographic and histologic evaluation of human periodontal defects treated with Bio-Oss and Bio-Gide. Int J Periodontics Restorative Dent 1998;18:321-331.

14. Camargo PM, Lekovic V, Weinlander M, Vasilic N, Madzarevic M, Kenney EB. Platelet-rich plasma and bovine porous bone mineral combined with guided tissue regeneration in the treatment of intrabony defects in humans. J Periodontol Res 2002;37:300-306.

15. Camelo M, Nevins ML, Lynch SE, Schenk RK, Simion M, Nevins M. Periodontal regeneration with an autogenous bone-Bio-Oss composite graft and a Bio-Gide membrane. Int J Periodontics Restorative Dent 2001; 21:109-119.

16. Anderegg C, Metzler D, Nicoll B. Gingiva thickness in guided tissue regeneration and associated recession at facial furcation defects. J Periodontol 1995 May, 66(5):397-402

17. Becker W, Becker B, Berg L, et al: New attachment after treatment with root isolation procedures: report for treated class II and class III furcations and vertical osseous defects, Int J Periodontics Restorative Dent 3:9, 1988.

18. Becker W, Becker BE, Berg L, et al: Clinical and volumetric analysis of three-wall intrabony defects following open flap debridement, J Periodontol 57:277, 1986.

19. Bowers GM, Chadroff B, Carnevale R, Mellonig J, Corio R et al. Histologic evaluation of new attachment apparatus formation in humans. Part III., J Periodontol. 1989 Dec; 60(12):683-93 
20. Mellonig JT. Human histologic evaluation of a bovine-derived bone xenograft in the treatment of periodontal osseous defects. Int J Periodontics Restorative Dent. 2000 Feb; 20(1):19-29.

21. Yukna RA, Mellonig JT. Histologic evaluation of periodontal healing in humans following regenerative therapy with enamel matrix derivative. A 10-case series. J Periodontol. 2000 May; 71(5):752-9

22. Camargo PM, Lekovic V, Weinlaender M, Klokkevold PR, Kenney EB et al. Influence of bioactive glass on changes in alveolar process dimensions after exodontia. Oral Surg Oral Med Oral Pathol Oral Radiol Endod. 2000 Nov; 90(5):581-6

23. Paolantonio M, Dolci M, Scarano A, d'Archivio D, et al. Immediate Implantation in Fresh Extraction Sockets. A Controlled Clinical and Histological Study in Man. J Periodontol 200 Nov.; 72(11):1560-71

\section{Corresponding author:}

Irena Georgieva,

Faculty of Dental Medicine,

84. Tsar Osvoboditel Blvd,

9000 Varna

email: dr.irenageorgieva@mail.bg 